\title{
Java Linux Administration Tool
}

\author{
Ahmed Bentiba, Ahmed Mohmed, Jamal Zemerly \\ Etisalat University College
}

Sharjah, United Arab Emirates

\begin{abstract}
The aim of this project is to design and implement a Linux tool for Linux administrators using Java programming language. This tool is called JLAT, Java Linux Administration Tool. JLAT will be portable to any Linux/Unix Operating Systems. This tool will contain the most popular and frequently used commands used by the Administrators of Linux/Unix systems. It has Arabic, English and French interfaces and can be easily translated to other languages.

This tool has been tested on Linux (Mandrake and Fedora 3 Red Hat) and on a commercial UNIX (Solaris 8) Operating systems. The JLAT has the advantages of having user friendly interfaces and it provides the system administrators with a centralized place for all administration tasks.
\end{abstract}

Index terms - COMPUTER languages, Computer science education, Computer network management, Operating systems, Java, Linux.

\section{Introduction}

The aim of this project is to provide Linux administrators with a tool to allow them do some tasks that are done manually through command line. Most frequent tasks in Linux and UNIX administration [1] are as follows: Add new users' accounts to the system, deleting users' accounts, changing users' passwords, check or set users quota and doing backups for important files in the system.

The goals of this project are: To design and produce a Linux administration tool using Java programming language, JLAT, to make the administration tool available by combining, in one central location, the most important functions Linux administrators use in their daily work. The users of this application will choose their interface language (Arabic, English or French) and to help the Linux [3] beginners to perform administration tasks easily in Graphical User Interface, GUI, without worrying about the Linux commands [4] that are executed behind the scenes.

The expected results: Expandable multilingual GUI that contains all popular functions of the Linux/Unix administration job. The result of each function will be shown to the user as an output message. Since Java language is portable [2] [5], therefore the JLAT tool will be portable to all Linux/Unix flavors,

\section{System Overview}

The JLAT tool is designed using the Java programming language and have an Arabic, English and French interface languages to allow the user to choose his or her preferred language.

The interaction between the user and the system can be viewed as client- server model [6]. The administrator sends a command to the system through the graphical user interface with some editable fields used to read the user data. The request is then executed and some messages will be displayed in a window to inform the administrator of the result of his request.

The following model shows clearly the cycle of interaction process between the user and the system. The general system architecture is shown in fig 1 .

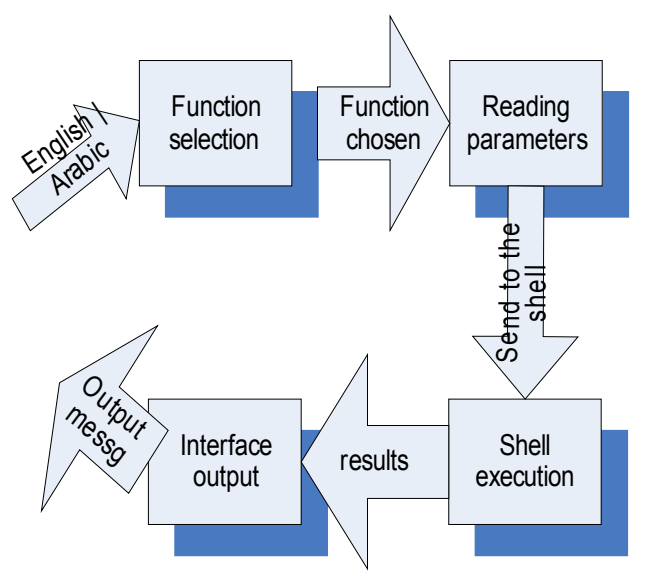

Figure 1 System Architecture

The JLAT tool is modular and it is decomposed into two main sections, user management section and server \& system monitoring section. Each section contains some functions as shown in fig 2. 


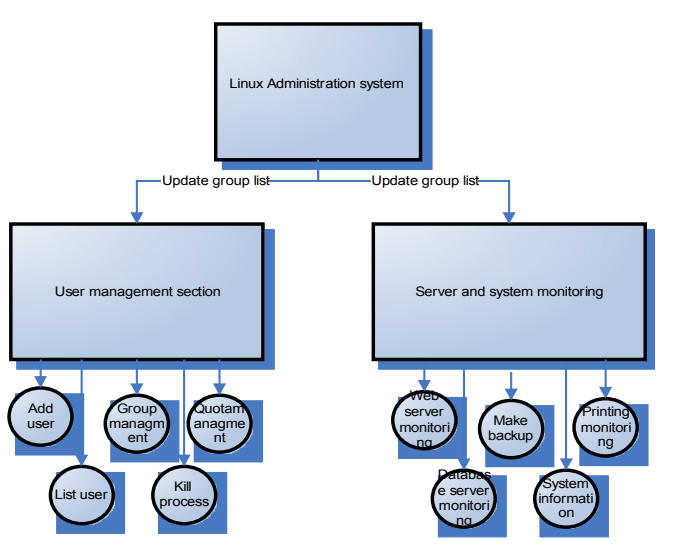

Figure 2 System decomposition

From the figure 2, the user management section contains the following functions: Add user, group management, list users in the system and stop a specific process for a specific user and managing quota for both users and groups.

The server and system monitoring section contains web server monitoring, in our case it is Apache server [7], database server monitoring, which is MySQL [8], making backup, display system information and finally printing job management.

\section{III.Implementation Issues}

\section{a. JLAT Commands}

Among the huge amount of Linux commands [14], [15], [16], some can be used by all users in the Linux system while many other commands are restricted to the super user or root user only for administering the system. Among these root commands, we gathered the most popular ones in this JLAT. As it is well known in system administration world, that only root or users with same rights as root can perform the administration tasks. Therefore the JLAT utility can be used by root only. We gathered in Table 1 all commands used in the user management section and commands used in the server and system monitoring section.

\begin{tabular}{|l|}
\hline Commands \\
\hline useradd \\
\hline autopasswd \\
\hline ps --user \\
\hline kill -9 "processId" \\
\hline /usr/sbin/edquota -u \\
\hline /usr/sbin/edquota - \\
\hline /usr/bin/quota -u \\
\hline /usr/bin/quota -g \\
\hline grouped "groupName" \\
\hline groupdel "selectedGroup" \\
\hline apachectl status/head -2 \\
\hline apachectl start \\
\hline /usr/sbin/mysqld --basedir=/ --data \\
\hline mysqladmin shutdown \\
\hline mysqladmin status \\
\hline tar cvfz /root/backup/back.tgz fileOrFolderName \\
\hline df -m/head -3 \\
\hline head -2 /proc/meminfo \\
\hline lpq \\
\hline lprm "fileId" \\
\hline
\end{tabular}

Table 1 Popular Linux administration commands

\section{b. User Interface Implementation}

The JLAT has been implemented to allow future extensions such as adding other administration tasks, adding translations to other languages and adding some themes to the existing ones.

\begin{tabular}{|l|l|}
\hline \multicolumn{1}{|c|}{ Widgets } & Purpose \\
\hline JPanel panel1 & $\begin{array}{l}\text { Define a panel called } \\
\text { panel1 }\end{array}$ \\
\hline JButton button1 & $\begin{array}{l}\text { Define a button called } \\
\text { button1 }\end{array}$ \\
\hline JTextField textFieald1 & Declare a text Field \\
\hline
\end{tabular}




\begin{tabular}{|l|l|} 
& called textField1 \\
\hline JTextArea textArea1 & $\begin{array}{l}\text { Used to define a text } \\
\text { Area called textArea1 }\end{array}$ \\
\hline JCheckBox check1 & $\begin{array}{l}\text { Define check Box } \\
\text { called check1 }\end{array}$ \\
\hline JComboBox comboBox & $\begin{array}{l}\text { Define a combo Box } \\
\text { called comboBox }\end{array}$ \\
\hline JTabbedPane tappedPane & Define a tapped pane \\
\hline JLabel label1 & Declare a label \\
\hline
\end{tabular}

Table 2 Some widgets used in JLAT

The JLAT tool is implemented into three different languages. The English and Arabic versions are shown in figure 3 and 4, respectively.

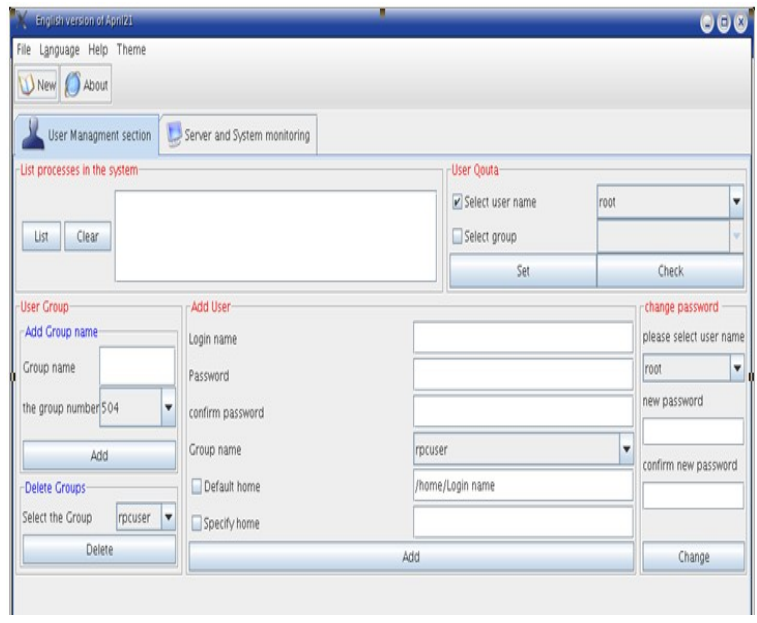

Figure 3 English version of JLAT

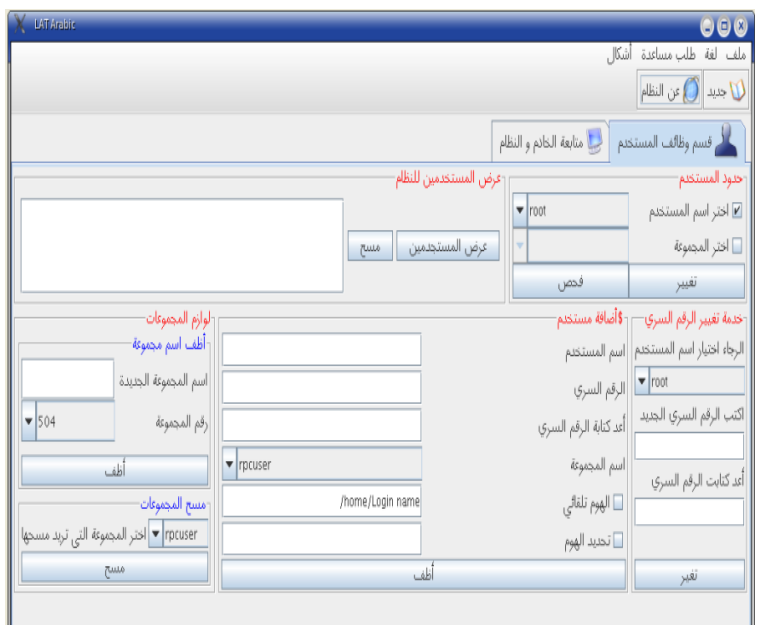

Figure 4 Arabic version of JLAT

\section{Project Results}

The JLAT tool has been implemented and it is divided into two main sections: User Management and System Monitoring. These two sections were tested using a set of scenarios for each function in Arabic, English and French languages. The following example shows a test case for "Add User Account" function in the English language.

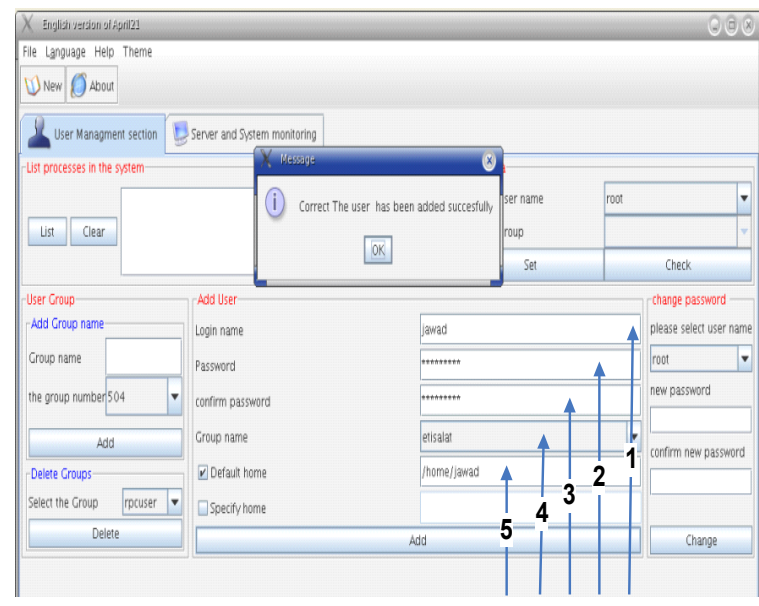

Figure 5 "Add User" function in English version of JLAT

The "Add User" function can be accomplished by following the arrow sequence on figure 5

Type the user name, which is in this example "jawad" then type the initial password "jawad1211" which is automatically encrypted. Confirm the password as pointed by arrow number (3) and Select the group name from the combo box that contains all group names available in the system. The default home directory will be created if the default check box selected. The home directory can be specified by the administrator by selecting the second check box "specify home" from the add user function.

This tool, JLAT, has been developed and tested carefully on Mandrake 10 Linux operating system [9]. It was ported and tested under Fedora Core 3 of Red Hat Linux [10], where exactly the same results have been obtained. In addition, the JLAT tool has been tested on a SUN (Solaris 8) machine [11], after solving a problem with the version of the Java compiler. The Java version used in the SUN machine was different of that of Linux's machines. Once the Java version was changed, the JLAT was working with most functions such as list users and add user to the system, add and delete groups, monitor processes and display system information such as disk space and 
the memory used.

We faced problems regarding the reading of Arabic files. We had to write the Arabic files using Unicode. We placed them in all widgets in the program rather than reading labels from text files.

Table 3 below shows main advantages and disadvantages of the implemented tool compared to other existing tools

\begin{tabular}{|c|c|c|c|}
\hline Tasks & JLAT & $\begin{array}{c}\text { Mandrake } \\
\text { Tool }\end{array}$ & $\begin{array}{c}\text { Red Hat } \\
\text { Tool }\end{array}$ \\
\hline $\begin{array}{l}\text { Language } \\
\text { used }\end{array}$ & JAVA & $\mathrm{QT}(\mathrm{C}++)$ & $\mathrm{QT}(\mathrm{C}++)$ \\
\hline Centralization & Yes & Yes & No \\
\hline $\begin{array}{l}\text { Support } \\
\text { different } \\
\text { languages }\end{array}$ & $\begin{array}{l}\text { Yes } \\
\text { (Arabic, } \\
\text { English, } \\
\text { French) }\end{array}$ & No & No \\
\hline Performance & Slower & Faster & Faster \\
\hline Portability & $\begin{array}{l}\text { Yes, it can } \\
\text { be run in } \\
\text { Mandrake, } \\
\text { Red hat, } \\
\text { Suse and } \\
\text { Solaris }\end{array}$ & $\begin{array}{l}\text { Only } \\
\text { specific } \\
\text { for } \\
\text { Mandrake } \\
\text { Operating } \\
\text { System }\end{array}$ & $\begin{array}{l}\text { Only } \\
\text { specific } \\
\text { for Red } \\
\text { Hat } \\
\text { Operating } \\
\text { System }\end{array}$ \\
\hline
\end{tabular}

Table 3 Comparison between JLAT tool and other tools

\section{Conclusions}

The Java Linux Administration Tool, JLAT, was designed and implemented successfully using Java language. The most popular Linux distributions from the following companies: Red Hat, Suse [12], Debian [13], Mandriva have their own administration tools. None of these tools are developed in Java. They are developed in $\mathrm{C}++$ (using Qt [17] Development Environment). We put in one centralized place the most frequent administration functions as in Suse and Mandriva, rather than making several tools as in Red Hat.

The unique features of JLAT are it is multilingual tool and it is written in Java language. The JLAT current version has Arabic, English and French interfaces and it can be easily expanded to include other languages. It can be ported to any Unix/Linux flavours on any architecture. These features are possible and inherited from the Java language.

\section{References}

[1] http://www.novell.com/documentation/suse10/index.html

[2] Eckel, B. Thinking in Java, Prentice Hall (2003)

[3] http:/www.linux.org

[4] http://www.computerhope.com/unix.htm\#05

[5] Horton, I. Beginning Java 2, Wrox (2002)

[6] Bradley, J. C. and Millspaugh, A. C. Programming with Java. McGraw Hill (2002)

[7] http://www.apache.org/

[8] http://www.mysql.com/

[9] http://wwwnew.mandriva.com/

[10] http://www.redhat.com/

[11] http://www.sun.com

[12] http://www.opensuse.org/

[13] http://www.us.debian.org/

[14] Sobel, M. G., A practical Guide to Linux, Addison Wesley (1977)

[15] Welsh, M. and Kaufman, L., Running Linux, O'Reilly \& Associates (1996)

[16] Hekman, J. P., Linux in a Nutshell: A Desktop Quick Reference, O'Reilly \& Associates (1997)

[17] http://www.trolltech.com/ 